\title{
Consider divergent regional perspectives to enhance wildlife conservation across Africa
}

\author{
In African wildlife conservation literature, southern and southeastern African voices dominate, giving a false \\ impression of pan-Africanism. We present divergent perspectives from West, Central and the Horn of Africa and \\ argue that empathy towards multiple perspectives offers increased resilience to COVID-19 and other crises.
}

\author{
Hans Bauer, Bertrand Chardonnet, Paul Scholte, Serge Alexis Kamgang, Djafarou Ali Tiomoko, \\ Aristide Comlan Tehou, Brice Sinsin, Fikirte Gebresenbet, Addisu Asefa, Kadiri Serge Bobo, \\ Hamissou Garba, Ali Laouel Abagana, Djibril Diouck, Ameer Awad Mohammed and \\ Claudio Sillero-Zubiri
}

$\mathrm{S}$ ub-Saharan Africa's wildlife conservation science and practice is dominated by experiences from southern Africa and the southern part of eastern Africa (henceforth SSE Africa - countries entirely south of the equator plus Uganda and Kenya but excluding Madagascar, Fig. 1). Stakeholders sometimes forget that the situation on the ground is different in West, Central and the Horn of Africa (henceforth WCH Africa - all other countries and in this case also including the 'interregional' Sudan, Fig. 1). In SSE Africa, neoliberal conservation under the slogan 'if it pays it stays' is driven by funding generated through tourism and various forms of wildlife utilization, underpinned by the private sector, supplemented by philanthropy channelled through civil society organizations, with governments providing an enabling environment, especially in terms of secure ownership or user rights of land and wildlife ${ }^{1}$. Note that Kenya does not allow consumptive use and generally does not support the commodification of wildlife, but its conservation sector is built on a large tourism industry and in that regard Kenya groups with SSE Africa. There is a lot of variation within SSE Africa and within WCH Africa, but less than there is between them, and the issue is broader than trophy hunting ${ }^{2}$.

English-language literature on African wildlife is dominated by SSE Africa; often WCH Africa is simply ignored, like in a 496-page book with SSE African cases only that has 15 statements about 'Africa' in the synthesis ${ }^{3}$. Some think there is no wildlife left in WCH Africa and consequently the SSE approach must be the only one in Africa $^{4}$. Others presumably extrapolate their SSE African experience, assuming there are no intrinsic differences, or more worryingly, blame media and animal rights and welfare organizations for misrepresenting a supposedly African narrative ${ }^{5}$. SSE African scholars have even portrayed decision makers as gullible, if not corrupt, rather than investigate why the two regions engage with non-governmental organizations on opposite ends of the sustainable use spectrum to serve the interests of their wildlife and people 6 .

Recently, Lindsey et al. looked at conservation of Africa's wildlife and wildlands through the COVID-19 crisis $^{7} ; 16$ of these author affiliations were from SSE Africa and 12 from outside Africa. They describe COVID-19 as a 'perfect storm' of reduced funding and restrictions on conservation operations to address elevated human threats, and surmise that this is a passing storm after which the existing approach must be intensified to contribute to greater resilience. Apart from the failure to recognize different health impacts of COVID-19 across Africa ${ }^{8}$, they imply that conservation impacts will be similar across the continent. Conservation scientists and practitioners in WCH Africa are less numerous and less vocal ${ }^{9}$, but many have a perspective that diverges from the SSE African model.

\section{The SSE African model}

Conservation in SSE Africa is underpinned by the idea that conservation is not zero-sum and should aim for win-win solutions that make wildlife economically self-supporting - the 'nature for people' framing ${ }^{10}$ consistent with 'if it pays it stays'. This has been successful in parts of southern Africa ${ }^{11}$, but it has also led to excesses in South Africa, like large captive wildlife populations, lion (Panthera leo) bone farming, cub petting, canned hunting, trophy hunting of exotic tigers (P. tigris), loss of wilderness (that is, systems with natural processes), landscapes scarred by fences and artificial water points and the classification of a host of wildlife species as domestic animals ${ }^{12-14}$. The win-win model was already showing limited resilience to rising management costs and reduced income leading to its abandonment in many areas ${ }^{15}$, accelerated by shifting public opinion on trophy hunting in the countries of origin of the 'clients' that are paying for the 'product' offered by the 'industry" ${ }^{2,15,16}$. Public opinion and academic discourse are also changing with reference to the association of wildlife conservation with militarization ('green wars') and racialized views and needs ('green colonialism'), challenging the sector's socio-political sustainability in the face of a galloping need for land ${ }^{17-22}$. In this context, it is important to be open minded about resilience to current and future shocks.

\section{WCH African approaches}

Conservation in WCH Africa has been less successful overall, with severe population declines and local extirpations, but the only known large mammal extinctions are the northern white rhino (Ceratotherium simum cottoni) and western black rhino (Diceros bicornis longipes) ${ }^{23-26}$. Importantly, good examples of success exist (see Box 1). Protected areas were often created in areas that were inaccessible due to disease or lack of infrastructure; many have lost substantial biodiversity and persist as paper parks, but others still protect viable functioning ecosystems through continued laissez faire or remoteness. Others are managed either by wildlife departments with a protectionist model, often supported by institutional donors, or by local communities, motivated by livelihoods or cultural values rather than finance - the 'people and nature' framing ${ }^{10,27,28}$. Wildlife-related revenues are 


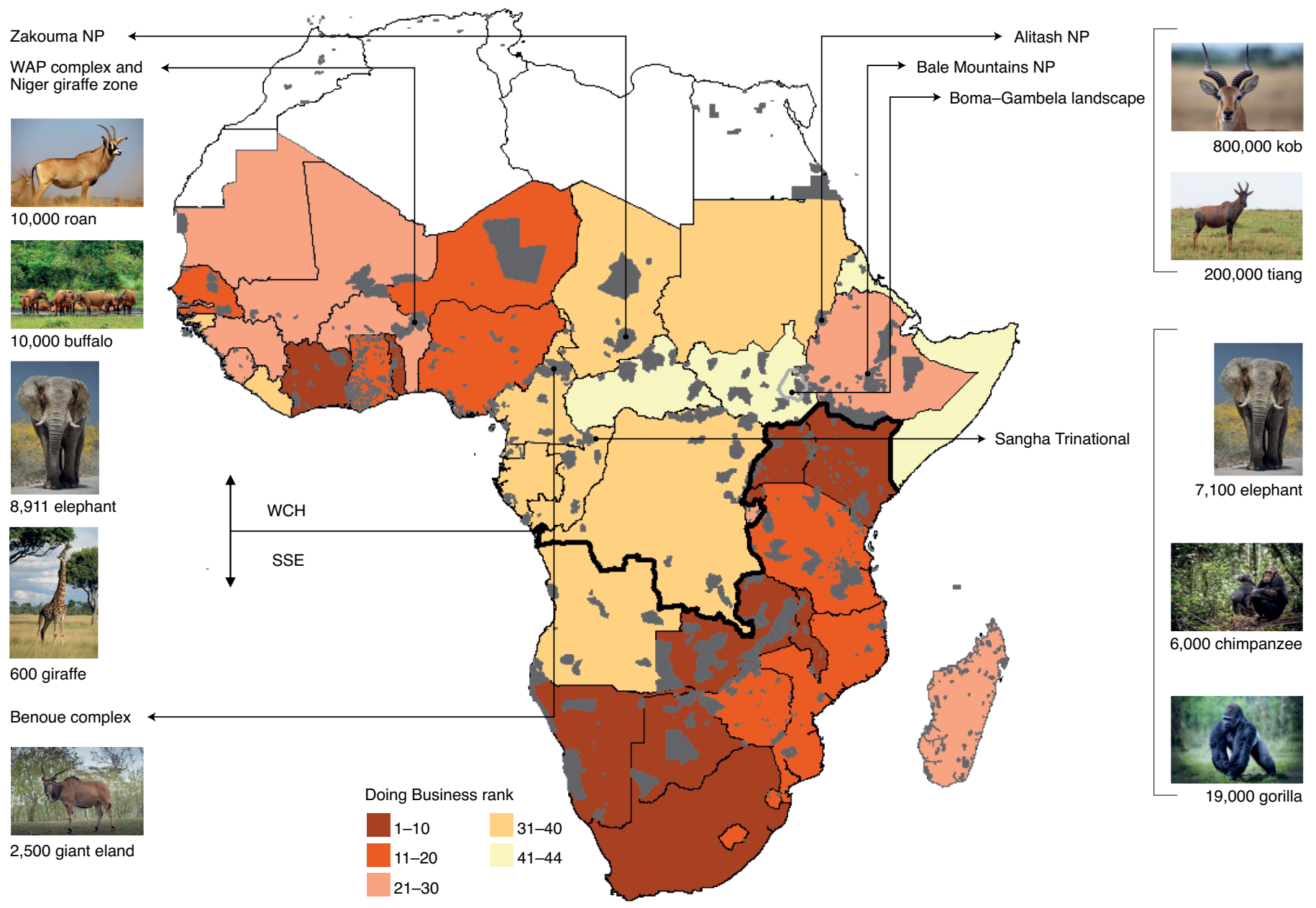

Fig. 1 | Sub-Saharan Africa with African Union regions divided into SSE Africa and WCH Africa. The shading shows World Bank Doing Business indices for sub-Saharan Africa ranked from the easiest (dark colour) to the most difficult (light colour) countries to start a business in. Category II-IV Protected Areas are in grey, taken from the World Database on Protected Areas (www.protectedplanet.net; accessed 25 September 2020) with name labels for areas mentioned in the text. Numbers below wildlife pictures indicate important populations mentioned in Box 1. Credit: Westend61 / Getty (roan); Danita Delimont / Alamy Stock Photo (buffalo); Raúl Barrero Photography / Moment / Getty (elephant); Jim Zuckerman / The Image Bank / Getty (giraffe); Buena Vista Images / Photodisc / Getty (giant eland); Claudio Bacinello / 500px / Getty (kob); Chaithanya Krishnan / Moment / Getty (tiang); Yannick Tylle / Corbis Documentary / Getty (chimpanzee); Mike Hill / Stone / Getty (gorilla).

sometimes of local importance, but overall they are small in comparison to other factors shaping people's behaviour, such as culture, education, rainfall, security and access to markets and services. Trophy hunting has been an important component in the provision of incentives in many countries in SSE Africa ${ }^{29}$; it has never been equally important across WCH Africa ${ }^{30}$ and is presently collapsing with few benefits, at limited spatial scales, at best delaying or slowing down wildlife declines ${ }^{15,31-33}$.

WCH African conservation practice does not have a single alternative model, but is often, by circumstance rather than design, closer to 'convivial conservation', a post-capitalist approach to human-wildlife coexistence $^{34,35}$. The WCH models are antithetical to neoliberal commodification, as illustrated by the slogan ' $100 \%$ Nature' used for many years by Pendjari National Park (NP), Benin (one of the most attractive in the region, yet with $<10,000$ visitors per year). Ecosystem services are emphasized along with existence values; in Ethiopia, Alitash NP was created to halt desertification and Bale Mountains NP is considered a water tower for millions of people ${ }^{36}$ but both also host threatened species, including lions. Rural policies, including those on land and wildlife property and user rights, are adapted to different regional priorities, institutions and cultures, not to an inexistent wildlife industry. Civil society and private sector mobilization around wildlife is marginal, and conservation is low on the political agenda. COVID-19 is currently affecting this situation through a reorientation of government and donor priorities, but much less through a reduction in the already meagre wildlife-related revenues.

With generally smaller wildlife populations, much lower revenues, and often more people to share them with, conservation in WCH Africa is seldom a win-win situation. Growing instability, persistent extreme poverty, endemic disease and a stifled civil society, against a background of lagging economic development make the SSE scenario unlikely in WCH Africa. This is compounded by the relatively low attraction that many of these remote areas offer to overseas visitors or influencers (tourists, philanthropists and celebrities), or their outright inaccessibility many such areas are almost entirely coloured 
Across WCH Africa in general, wildlife is naturally less abundant due to lower productivity of ecosystems ${ }^{55}$, and population declines have been more severe due to anthropogenic threats ${ }^{23}$. However, there are robust and stable populations of key species and cases of successful conservation in key protected areas; we present some examples (see also Fig. 1).

(1) W-Arly-Pendjari (WAP) complex, Benin-Niger-Burkina Faso. The WAP complex is a $\sim 20,000 \mathrm{~km}^{2}$ transfrontier conservation area (established before these were 'pioneered' in SSE Africa) and a World Heritage Site (https://whc. unesco.org/en/list/749/; accessed 14 September 2020). Funding from national governments has been generously supplemented through different modalities; projects supported by many donors (especially the European Union and Germany) worth over US $\$ 50$ million since 2000, a US\$28 million trust fund, and recently delegation of management of the Benin components to African Parks with a pledge of US\$25 million from different partners. Despite known inefficiencies in spending and short gaps between projects, the complex has effectively had stable populations, with $\sim 10,000$ roan antelope (Hippotragus equinus) and $~ 10,000$ buffalo (Syncerus caffer), and a doubling of the elephant (Loxodonta africana) population to 8,911 since $2003^{56}$.

(2) Niger giraffe. Outside formally protected areas, but just $\sim 100 \mathrm{~km}$ from the WAP complex, Niger has the only remaining population of West African giraffe (Giraffa camelopardalis peralta) and their numbers grew from 49 in 1996 to 600 in $2000^{57}$.

(3) Zakouma NP, Chad. Part of the $\sim 30,000 \mathrm{~km}^{2}$ Greater Zakouma Ecosystem, Zakouma NP received substantial international support for over 35 years from a succession of projects mainly funded by the European Union. Wildlife populations show high densities and have been stable but elephants suffered from a short period of intense poaching in the beginning of this century, and populations are recovering ${ }^{46}$.

(4) Sangha Trinational (TNS), Cameroon-Congo-Central African Republic (CAR). The $\sim 44,000 \mathrm{~km}^{2}$ TNS in the Congo Basin is a stronghold for forest species (https://whc.unesco.org/en/ list/1380/; accessed 14 September 2020). National Parks within the TNS have had individual funding, but the most robust fund currently is a US\$60 million trust fund $^{46}$. About half the area (Cameroon and CAR components) was surveyed in 2014 and 2016, showing a density of 0.31 elephants and 1.11 weaned great apes per $\mathrm{km}^{2}$ (7,100 elephants, 19,000 gorillas (Gorilla gorilla) and 6,000 chimpanzees (Pan troglodytes) $^{58}$.

(5) Benoue complex, Cameroon. The $\sim 20,000 \mathrm{~km}^{2}$ Benoue complex in Cameroon has had mixed success with severe declines in some parts but stability in others ${ }^{59}$; of global importance is the population of $\sim 2,500$ giant eland (Tragelaphus derbianus) ${ }^{60}$.

(6) Boma-Gambela landscape, South Sudan-Ethiopia. The biggest migration after Serengeti-Mara but little known and witnessed by few, $\sim 800,000$ white-eared kob (Kobus kob leucotis) migrate every year over $\sim 900 \mathrm{~km}$ across the vast and remote landscape between Boma NP in South Sudan and Gambela NP in Ethiopia, along with possibly 200,000 tiang (Damaliscus korrigum tiang) ${ }^{61}$. red and orange on most western countries' travel advisories. The figure of annual tourist arrivals (fig. 4e in ref. ${ }^{7}$ ) looks deceptively homogeneous with large countries like Nigeria, Sudan and Ethiopia showing up in blue, but these three countries have little wildlife tourism - the number of National Park visitors is highest in Ethiopia where gate fees totalled a paltry US $\$ 19,000$ in $2009^{37}$. A more meaningful metric is the World Bank Doing Business ranking (www.doingbusiness. org; accessed 11 September 2020), as a proxy for the challenges to the WCH African private sectors that stymy the development of a tourism industry and the capitalization of wildlife commodities (Fig. 1).

\section{One size does not fit all}

'If it pays it stays' is rarely applicable for the current generation of practitioners and policy makers in WCH Africa. This is not unique to the region; wildlife conservation throughout the world actually depends to a large degree on public subsidies, seen as a legitimate cost to local and global society $^{38,39}$. The model embraced by SSE Africa can have undesirable consequences elsewhere in the continent; international wildlife trade policies that aim to increase the value of wildlife with the intention to provide community benefits and to fund law enforcement may have adverse consequences in WCH Africa, where stakeholders are unable to accrue those values but face increased costs to protect increasingly valuable resources. The extinction of two rhino subspecies in $\mathrm{WCH}$ Africa is a regional failure and cannot be blamed on SSE Africa, but it certainly did not help that SSE Africa has always aimed to increase the commercial value of rhino horn $^{40}$. For WCH Africa, legal trade in elephant ivory ${ }^{41}$ and lion bone ${ }^{42}$ are similarly challenging.

Ultimately, funding is the critical determinant of success in wildlife conservation $^{43-45}$. Lindsey et al. ${ }^{7}$ also point this out and do make a set of useful recommendations about international funding, but they focus on improving opportunities for a wildlife-based economy; we doubt the general validity of those recommendations across sub-Saharan Africa especially without an analysis of profitability and risks. We similarly doubt that their recommendations relative to the public sector and civil society are cogent for $\mathrm{WCH}$ Africa at present.

Clearly, a single framing for terrestrial conservation does not fit across a vast and diverse continent. Alternative perspectives are important, and certainly for WCH Africa, where funding streams from institutional donors eclipse the importance of all other mechanisms ${ }^{15,46}$. Considering the global benefits of wildlife conservation in Africa and the widely recognized need for the international community to contribute to the costs, international solidarity is a more substantial, resilient and sustainable source of funding, definitely for $\mathrm{WCH}$ Africa. The key to results on the ground lies with management effectiveness and various models of delegated or collaborative management have been successful; with bilateral aid and various other institutional funds channelled through government there will be a continuing role for models that rely on the provision of technical and financial support to wildlife departments as implementing agencies ${ }^{46,47}$. 


\section{An African conservation paradox}

The COVID-19 pandemic has brought global hardship; it will most certainly have negative impacts on wildlife conservation across Africa, but in WCH Africa, the concurrent but unrelated wave of armed conflict and political instability may have far more impact. Violent histories, insurgents and terrorists have created chaos in several protected areas ${ }^{48,49}$ and jihadists have used them as their base ${ }^{50,51}$. The impacts of insecurity are created partially by mechanisms analogous to COVID-19 (for example, restrictions on law enforcement activities, further reduction of any residual tourism, redirection of funds), but also by the large-scale burning of wildlands as a military tactic, the use of wildlife for sustenance by fighting parties, and the perceived security risk of having extensive wildlands uninhabited by people and controlled by armed forces under command of wildlife departments rather than the conventional armed forces ${ }^{48,52}$. The two regions appear to have different 'perfect storms' somehow creating a paradox that mires a pan-African mitigation strategy.

The differences in the contrasting perspectives presented here have high policy relevance. International debates are often split across Africa, especially at the Convention on International Trade in Endangered Species of Wild Fauna and Flora (CITES) ${ }^{41}$, to the point where Southern African Development Community (SADC) countries threatened to withdraw from the convention at the last Conference of Parties ${ }^{53}$. While pursuing the same objective, but with different perspectives, the probability of a shared African conservation strategy is low, as the two halves of Africa are pitted against each other on opposite ends of sustainable use policies. This opens up the debate to strong influence from the Global North where perspectives are equally divided ${ }^{54}$, making for further politization and escalation ${ }^{42}$. Biggs et al. ${ }^{41}$ call for improved debate towards collective action within Africa; in the absence of a pan-African consensus we add that empathy towards multiple perspectives, reflecting African diversity, is crucial to reach coherence in wildlife policy across Africa.

Hans Bauer D1,2四, Bertrand Chardonnet ${ }^{3}$, Paul Scholte ${ }^{4}$, Serge Alexis Kamgang (D), Djafarou Ali Tiomoko ${ }^{4}$,

Aristide Comlan Tehou, ${ }^{6}$, Brice Sinsin ${ }^{6}$, Fikirte Gebresenbet (iD) ${ }^{7}$ Addisu Asefa8, Kadiri Serge Bobo ${ }^{9}$, Hamissou Garba ${ }^{10}$,
Ali Laouel Abagana", Djibril Diouck ${ }^{12}$, Ameer Awad Mohammed ${ }^{13}$ and Claudio Sillero-Zubiri $i^{1,14}$

${ }^{1}$ Wildlife Conservation Research Unit, Recanati-Kaplan Centre, Zoology, University of Oxford, Oxford, UK. ${ }^{2}$ Evolutionary Ecology Group, Biology, University of Antwerp, Antwerp, Belgium. ${ }^{3}$ African Protected Areas and Wildife, Saint Cloud, France. ${ }^{4}$ Biodiversity Conservation, German International Cooperation (GIZ), Abidjan, Côte d'Ivoire. ${ }^{5}$ Garoua Wildlife College (EFG), Garoua, Cameroon. ${ }^{6}$ Laboratory for Applied Ecology, Natural Resource Conservation, University of Abomey-Calavi, Cotonou, Benin. ${ }^{7}$ Biology, Luther College, Decorah, IA, USA. ${ }^{8}$ Protected Areas Estate Project, Ethiopian Wildlife Conservation Authority, Addis Abeba, Ethiopia. ${ }^{9}$ Department of Forestry, University of Dschang, Dschang, Cameroon. ${ }^{10}$ Protected Areas Division, Ministry of Environment and Sustainable Development, Niamey, Niger. ${ }^{11}$ Project Sustainable Management of Biodiversity, Ministry of Environment and Sustainable Development, Niamey, Niger. ${ }^{12}$ National Parks Directorate, Ministry of Environment and Sustainable Development, Dakar, Senegal. ${ }^{13}$ Wildlife Research Centre, Khartoum, Sudan. ${ }^{14}$ The Born Free Foundation, Horsham, UK.

$凶_{e-m a i l: H a n s . b a u e r @ z o o . o x . a c . u k}$

Published online: 2 November 2020 https://doi.org/10.1038/s41559-020-01343-6

\section{References}

1. Lindsey, P. A., Roulet, P. A. \& Romañach, S. S. Biol. Conserv. 134, 455-469 (2007).

2. Bauer, H., Chardonnet, B., Jones, M. \& Sillero-Zubiri, C. Science 366, 433-434 (2019)

3. Prins, H. H. T. \& Grootenhuis, J. G. in Wildlife Conservation by Sustainable Use (eds Prins, H. H. T. et al.) 1-12 (Springer, 2000).

4. Abensperg-Traun, M. Biol. Conserv. 142, 948-963 (2009).

5. Hart, A. G. et al. Conserv. Biol. https://doi.org/10.1111/cobi.13605 (2020).

6. Madzwamuse, M., Rihoy, E. \& Louis, M. Development 63 67-73 (2020).

7. Lindsey, P. et al. Nat. Ecol. Evol. 4, 1300-1310 (2020).

8. Mehtar, S. et al. Lancet Glob. Health 8, E881-E883 (2020).

9. Hickisch, R. et al. Conserv. Biol. 33, 1151-1163 (2019).

10. Mace, G. M. Science 345, 1558-1560 (2014).

11. Bauer, H. et al. Proc. Natl Acad. Sci. USA 112, 14894-14899 (2015).

12. Harvey, R. G. Glob. Ecol. Conserv. 23, e01157 (2020).

13. Shrader, A. M., Pimm, S. L. \& van Aarde, R. J. Biodivers. Conserv. 19, 2235-2245 (2010).

14. Michael, J. S. et al. S. Afr. J. Sci. 116, 7724 (2020)

15. Chardonnet, B. Africa is Changing: Should its Protected Areas Evolve? Reconfiguring the Protected Areas in Africa (IUCN, 2019). 16. Dickman, A. et al. Science 365, 874 (2019).

17. Bauer, H., Gebresenbet, F., Kiki, M., Simpson, L. \& Sillero-Zubiri, C. Front. Ecol. Evol. 7, 24 (2019).

18. Mollett, S. \& Kepe, T. Land Rights, Biodiversity Conservation and Justice: Rethinking Parks and People (Routledge, 2018).

19. Brockington, D. \& Wilkie, D. Phil. Trans. R. Soc. B 370, 20140271 (2015).

20. Büscher, B. \& Fletcher, R. Conserv. Soc. 16, 105-113 (2018).

21. Garland, E. Afr. Stud. Rev. 51, 51-74 (2008).

22. Mkono, M. J. Sustain. Tour. 27, 689-704 (2019).

23. Mallon, D. P. et al. An IUCN Situation Analysis of Terrestrial and Freshwater Fauna in West and Central Africa. Occasional Paper of the IUCN Species Survival Commission No. 54 (IUCN, 2015).
24. Brugière, D., Chardonnet, B. \& Scholte, P. Trop. Conserv. Sci. 8, 513-527 (2015).

25. Henschel, P. et al. PLoS ONE 9, e83500 (2014).

26. Scholte, P. Trop. Conserv. Sci. 4, 1-11 (2011).

27. Asefa, A., Mengesha, G. \& Almaw, R. Conserv. Sci. Pract. 1, el13 (2019).

28. Ashenafi, Z. T., Leader-Williams, N. \& Coulson, T. Conserv. Soc. 10, 209-216 (2012).

29. Creel, S. et al. Ecol. Appl. 26, 2347-2357 (2016)

30. Lindsey, P. A., Frank, L. G., Alexander, R., Mathieson, A. \& Romañach, S. S. Conserv. Biol. 21, 880-883 (2007).

31. Bauer, H. et al. PLoS ONE 12, e0173691 (2017).

32. Aebischer, T. et al. Biol. Conserv. 241, 108326 (2020).

33. Lescuyer, G., Ngouhouo Poufoun, J., Defo, L., Bastin, D. \& Scholte, P. Int. For. Rev. 18, 108-118 (2016).

34. Büscher, B. \& Fletcher, R. The Conservation Revolution: Radical Ideas for Saving Nature Beyond the Anthropocene (Verso Trade, 2020).

35. Fletcher, R., Büscher, B., Massarella, K. \& Koot, S. J. Aust. Political Econ. 85, 200-211 (2020).

36. Chignell, S. M., Laituri, M. J., Young, N. E. \& Evangelista, P. H. Ann. Am. Assoc. Geogr. 109, 791-811 (2019).

37. Assessment of the Value of the Protected Area System of Ethiopia, "Making the Economic Case" (Ethiopian Wildlife Conservation Authority, 2009).

38. Balmford, A. \& Whitten, T. Oryx 37, 238-250 (2003).

39. Balmford, A., Gaston, K. J., Blyth, S., James, A. \& Kapos, V. Proc. Natl Acad. Sci. USA 100, 1046-1050 (2003).

40. Clements, H. S., Knight, M., Jones, P. \& Balfour, D. Conserv. Lett. https://doi.org/10.1111/conl.12741 (2020).

41. Biggs, D. et al. Science 358, 1378-1381 (2017).

42. Bauer, H., Nowell, K., Sillero-Zubiri, C. \& Macdonald, D. W. Conserv. Lett. 11, e12444 (2018).

43. Packer, C. et al. Ecol. Lett. 16, 635-641 (2013).

44. Lindsey, P. A. et al. Biol. Conserv. 209, 137-149 (2017).

45. Lindsey, P. A. et al. Proc. Natl Acad. Sci. USA 115 , E10788-E10796 (2018).

46. Scholte, P. et al. Trop. Conserv. Sci. 11, 1940082918796621 (2018).

47. Baghai, M. et al. Biol. Conserv. 218, 73-82 (2018).

48. Lombard, L. Geoforum 69, 218-226 (2016).

49. Pennaz, A. K., Ahmadou, M., Moritz, M. \& Scholte, P. Conserv Soc. 16, 125-135 (2018).

50. Paquette, D. Burkina Faso's wildlife reserves have become a battle zone, overrun by militants and poachers. The Washington Post (13 September 2020); https://go.nature.com/3nQtD6Y

51. McGregor, A. Sudanese Security Forces Raid Islamist Training Camp in National Park (Jamestown Foundation, accessed 14 September 2020) https://go.nature.com/33WQcPF

52. Kelly, A. B. \& Ybarra, M. Geoforum 69, 171-175 (2016).

53. Southern African nations threaten to quit wildlife trade monitor. news24 (1 September 2019); https://go.nature. com/317ha59

54. Macdonald, D. W. et al. Mammal Rev. 47, 247-253 (2017).

55. East, R. Afr. J. Ecol. 22, 245-270 (1984).

56. Chase, M. J. et al. PeerJ 4, e2354 (2016)

57. West African giraffe are going from strength to strength. Giraffe Conservation Foundation (24 January 2020); https:// go.nature.com $/ 2 \mathrm{FrORH} 0$

58. N'Goran, P. K. WWF Biomonitoring activities from 2014 to 2016: Status of Forest Elephant and Great Apes in Central Africa Priority Sites (WWF Africa Program, 2017).

59. Bakker, C. E. et al. Eur. J. Wildl. Res. 66, 82 (2020).

60. Elkan, P. et al. Aerial Surveys of Wildlife and Human Activity Across the Bouba N'djida - Sena Oura - Benoue - Faro Landscape, Northern Cameroon and Southwestern Chad (Wildlife Conservation Society, 2015).

61. Schapira, P., Monica, M., Rolkier, G. G. \& Bauer, H. Oryx 51, 19 (2016).

\section{Author contributions}

H.B., B.C., P.S. and C.S.-Z. conceptualized and wrote the text, S.A.K. prepared the figure and D.A.T., A.C.T. B.S., F.G., A.A., K.S.B., H.G., A.L.A., D.D. and A.A.M. edited the text.

Competing interests

The authors declare no competing interests. 